\title{
Changes in air pollutant emissions from road vehicles due to autonomous driving technology: A conceptual modeling approach
}

\author{
Ha Hwang ${ }^{1}$, Chang-Keun Song ${ }^{+}$ \\ ${ }^{1}$ Division of Disaster \& Safety Research, Korea Institute of Public Administration, Seoul 03367, Republic of Korea \\ ${ }^{2}$ School of Urban and Environmental Engineering, Ulsan National Institute of Science and Technology, Ulsan 44919, Republic of Korea
}

\begin{abstract}
The autonomous vehicles (AVs) could make a positive or negative impact on reducing mobile emissions. This study investigated the changes of mobile emissions that could be caused by large-scale adoption of AVs. The factors of road capacity increase and speed limit increase impacts were simulated using a conceptual modeling approach that combines a hypothetical speed-emission function and a traffic demand model using a virtual transportation network. The simulation results show that road capacity increase impact is significant in decreasing mobile emissions until the market share of AVs is less than $80 \%$. If the road capacity increases by $100 \%$, the mobile emissions will decrease by about $30 \%$. On the other hand, driving speed limit increase impact is significant in increasing mobile emissions, and the environmentally desirable speed limit was found at around $95 \mathrm{~km} / \mathrm{h}$. If the speed limit increases to $140 \mathrm{~km} / \mathrm{h}$, the mobile emissions will increase by about $25 \%$. This is because some vehicles begin to bypass the congested routes at high speeds as speed limit increases. Based on the simulation results, it is clear that the vehicle platooning technology implemented at reasonable speed limit is one of the AV technologies that are encouraging from the environmental point of view.
\end{abstract}

Keywords: Autonomous vehicles, Conceptual modeling approach, Mobile emissions, Road capacity, Speed limit

\section{Introduction}

This study discusses the environmental impacts of large-scale autonomous vehicle (AV) adoption in order to explore desirable directions of AV technologies and policies from the environmental perspective. It is expected that AVs will solve problems in many areas including the environmental field, but this optimism requires continued efforts of various fields including environmental science, social science, and urban and transportation planning to keep the development of AV technologies and policies environmentally sustainable [1]. The technologies of AV are in the final stages, and experts predict that AVs will be available to the public by 2030 at the latest [2-7]. While mixed forces of increasing or decreasing mobile emissions caused by AVs are expected, there has been little in-depth discussion about their potential impacts [1]. Automobiles are one of the biggest sources of air pollution and demand for them is increasing [8-10]. Air pollution caused by excessive use of fossil

This is an Open Access article distributed under the terms of the Creative Commons Attribution Non-Commercial License (http://creativecommons.org/licenses/by-nc/3.0/) which permits unrestricted non-commercial use, distribution, and reproduction in any medium, provided the original work is properly cited.

Copyright (C) 2020 Korean Society of Environmental Engineers fuels is one of mankind's most daunting challenges. Nonetheless, most countries' socio-economic systems are still fossil fuel-dependent, and the development of clean energy to replace them has not come to fruition. Transportation contributes approximately $28 \%$ of greenhouse gas (GHG) emissions generated by human activity [11]. Given the increasing trends of interregional and international trade [12], the GHG emissions from the transportation sector are expected to increase further. Moreover, the increase in traffic congestion is intensified in populated areas due to the imbalance in traffic demand and supply, and this has caused more immediate exposure of mobile pollution to people. In order for AV to become a solution to such problems, multidisciplinary discussions should be made on the way of developing and adopting AVs to make larger environmental benefit [1].

As part of this context, this study analyzed the impacts of road capacity increase due to platooning and speed limit increase on mobile emissions. AVs will have incredibly improved string stability
Received March 21, 2019 Accepted May 21, 2019
${ }^{\dagger}$ Corresponding author
Email: cksong@unist.ac.kr
Tel: +82-52-217-2835
ORCID: 0000-0002-8987-2176 
which is based on vehicle-to-vehicle(V2V) technology that is essential element of AVs because it enables cooperative operation between vehicles, and managing extremely narrow inter-vehicle distances will be possible $[2,13]$. As the inter-vehicle distance decreases, the transportation network can accommodate more vehicles, resulting in an increase in traffic capacity [14]. As market-penetration level of vehicles with this technology increases to $50 \%, 80 \%$, and $100 \%$, traffic capacity increases by $18 \%, 49 \%$ and $80 \%$, respectively, when inter-vehicle distance is set about $0.7 \mathrm{~s}$ [15]. Our concern is the environmental impact when the inter-vehicle distance (in seconds or meters) becomes smaller. In addition, AVs will be able to manage faster vehicle speed without compromising safety with the help of V2V and vehicle-to-infrastructure (V2I) technologies $[1,16,17]$. V2I technology is a type of Intelligent Transportation System (ITS) that provides real-time traffic information between vehicles and road facilities [18, 19]. V2I technology research originally started with the aim of improving safety by providing driving information to drivers, but has developed into a study for fuel optimization through optimal gear shifting [20] and minimizing operation of brakes and excels [21]. Talebpour and Mahmassani [22] verified the effect of AVs on improving the traffic flow stability by simulating different vehicle types and distinct communication capability situations. However, improved string stability and traffic flow stability can increase vehicle speed [1, 16, 17, 23]. In congested city centers, mobile emissions may decrease due to increase in traffic speed, but mobile emissions may seriously increase when high-speed driving occurs on highways. In areas where just-in-time services are important, such as cargo transportation, shortening travel times is a very important issue. Some people may argue that AVs cannot be allowed to run beyond the current speed limit due to safety issue. Nevertheless, it is practically difficult to limit the maximum speed of an AV if it is owned by an individual because the purpose of a travel is to reach to a destination quickly and safely. If safety increases significantly, a traveler will choose to go faster while sacrificing safety to some degree [1, 23]. Therefore, this claim may be possible when AVs are adopted as a form of the semi-public transportation system. However, whether this restriction is environmentally preferable is an important issue that determines the ultimate direction of AVs. Our concern is the environmental impact when mitigating the speed limit.

Likewise, the prospects for AVs are mingled with positive and negative environmental impacts, and platooning and increased speed are one of them $[1,17]$. It is unclear whether the adoption of AVs in large-scale with both of these technologies will have a positive impact on the environment and will be a solution to the problems raised above. Previous studies argue that AVs will have positive effects in improving the level of service in the congested area and smoothing traffic flow [24], and the fuel economy would be significantly improved [25]. These studies, however, are the results of measuring the effects at the individual vehicle level by testing on a driving circuit without traffic or conducting a mathematical calculation, and did not take into account the complicated mechanism within the traffic system. For example, traffic flow of a congested route becomes smoother when inter-vehicle distance decreases, but it becomes worse to some extent because other vehicles begin to use the improved route to reduce travel time. Also, some vehicles will choose a longer route instead of a shorter but congested route if high-speed driving become feasible, and this will improve the traffic flow of the congested route.

In this study, we investigated how the adoption of AVs works in a traffic system, and what is the consequent environmental outcome. We especially focused on the effects of road capacity increase due to platooning and speed limit increase on mobile emissions. Three scenario simulations including the null scenario (Scenario 1) simulation were conducted using a conceptual modeling approach (CMA). The null scenario simulation result is a snapshot of a situation where the road capacity is fixed and the speed limit is $100 \mathrm{~km} / \mathrm{h}$, which is a normal level. The result of Scenario 1 was used as a baseline scenario to illustrate the current situation to be compared with the results of Scenario 2 and Scenario 3. Scenario 2 simulates situations where the speed limit is unchanged and the road capacity increases from $0 \%$ to $100 \%$. Scenario 3 simulates situations where the road capacity is fixed and the speed limit changes from $60 \mathrm{~km} / \mathrm{h}$ to $140 \mathrm{~km} / \mathrm{h}$. The maximum speed limit was set based on the average speed of German Autobahn [26]. The Methods section summarizes CMA and assumptions adopted in this study. The simulation results and their implications were summarized in Results and Discussion section.

\section{Methods}

\subsection{Conceptual Modeling Approach}

We used CMA, which combines a traffic demand model and a virtual speed-emission function. Previous studies have investigated the environmental impacts of AVs and provided insightful findings with technical details. These studies have identified the impact of the cruise control systems, which enable autonomous driving [21, 27], or the car-following mechanism [28-31] that enables vehicle platooning to improve fuel economy and reduce mobile emissions. In addition, most of vehicular emission studies have used micro-simulation models such as VISSIM that can reflect driving dynamics and behavior with detailed traffic conditions and vehicle profiles and MOVES in order to estimate the detailed emission profiles by vehicle type, model year, and emission gas of a specific geographical boundary [32-35]. This is because driving dynamics and vehicle profiles are critical factors for estimating mobile emissions. Significant amount of mobile emissions is generated in accelerating situations, and more than a hundred times of mobile emissions are generated from an old heavy-duty vehicle than the newest light-weight vehicle.

However, CMA is a combination of the macro-simulation model and the virtual speed-emission function. When AVs are introduced, the driving dynamics of all vehicles will become similar regardless of drivers' driving behavior or capability. This is because at the moment of boarding an AV, a driver is no longer a driver but a passenger. All AVs will drive at similar speeds to nearby AVs, and will only change lanes if necessary. One thing we have missed in the current study is the mobile emission reduction effect through minimizing the process of stop, idling, and start at the traffic lights due to traffic flow optimization. While measuring this effect is out of scope at this time, it is expected to be particularly large 
in urban areas where traffic lights are many and traffic volume is high. These effects should be measured through experimental studies henceforth. From this point of view, we set assumption 1 as follow.

Assumption 1. There is no speed variance among vehicles in the same link, and the emissions due to stop-and-go are ignored.

CMA is not suitable for predicting accurate mobile emissions by vehicle profile and pollution sources, but this approach is appropriate for the macroscopic exploration of the environmental impact of new changes. The emission functions differ depending on the fuel type, vehicle type, and model year of a vehicle. However, the purpose of this study is not to predict changes in specific areas based on measured traffic volume and fleet composition, but it is a conceptual study to investigate the effect of changes in driving characteristics on the emission of AVs. The temporal assumption of this simulation study is not the present, but the near future around 2030, when AVs will be adopted in large-scale. At this time, old diesel vehicles will no longer run on the roads and the vehicles that meet the Euro5 or above environmental standards will occupy the majority. Accordingly, after 2030, the difference among emission functions caused by the vehicle characteristics is expected to be reduced. Nevertheless, it should be made clear that the results of this study do not reflect the differences in emissions due to vehicle characteristics. From this point of view, we set assumption 2 as follow. With this assumption, this study introduces a hypothetical speed-emission function explained in section 2.3 to simplify simulation settings.

Assumption 2. All vehicles are of the same model and same year, and emit the same amount under the same conditions.

The purpose of CMA is not to calculate the detailed emission profile of specific regions but rather to examine the macroscopic effects of AV technology on the environment and to suggest the directions of related technology and policy development. From this point of view, we set assumptions 3 and 4 as follow.

Assumption 3. Vehicle emissions are assumed to be one composite material.

Assumption 4. The virtual test network is flat and there are no additional mobile emissions due to acceleration by slopes.

\subsection{Traffic Demand Model}

Traffic demand model is the traffic forecasting method, which is also known as the four-step procedure model or four-stage procedure model [36]. This method works through the four sequential analysis processes: trip generation, trip distribution, modal split, and traffic assignment. Every analysis step reflects individual decisions based on human behavioral characteristics [37]. In this study, we skipped the first three stages by adopting the traffic OD-matrix provided by LeBlanc et al. [38], and simulated only the final stage. Traffic assignment is the step determining which travel routes may be chosen by assigning the traffic demand to transportation networks.

In order to eliminate the variance of mobile emissions due to the difference of traffic situations and geographical conditions among regions, this study used a virtual transportation network rather than a transportation network of a region. LeBlanc et al. [38] provided the virtual transportation network which is consists of 76 links and 24 nodes. We also adopted the same link-performance function [39] and the related parameters, and the traffic demand OD-matrix from the study. While the prospect that traffic demand will increase when AVs are introduced is dominant, it is not clear where and how much will increase. Since the purpose of this study is not to estimate the change of mobile emissions due to the increase of traffic demand, we set assumption 5 as follow.

Assumption 5. Traffic demand is fixed.

In order to allocate the traffic demand which can assume the average traffic situation, the traffic demand which satisfies the average link speed of $60 \mathrm{~km} / \mathrm{h}$ is obtained. To find this level of traffic demand, the traffic demand OD-matrix, which was provided by LeBlanc et al. is multiplied by $\alpha$, and then assigned to the network. The $\alpha$ value satisfying the average link speed of $60 \mathrm{~km} / \mathrm{h}$ was found by performing simulations to find the user equilibrium state while changing the $\alpha$ value. The standard deviation of 76 links was $24.74 \mathrm{~km} / \mathrm{h}$ at this traffic condition, and the link speed is evenly distributed between $100 \mathrm{~km} / \mathrm{h}$ and $20 \mathrm{~km} / \mathrm{h}$. Traffic assignment was conducted with the Frank-Wolfe algorithm [40] $(\lambda=$ 0.1 , iteration $=50$ ). The model was coded and run using the programming language $\mathrm{R}$ (v.3.5.1).

\subsection{Speed-Emission Function}

We used a hypothetical speed-emission function rather than predefined speed-emission functions by vehicle types, vehicle years, and pollutant types. The function has a concave curve that decreases and increases as vehicle speed increases (Eq. (1)). The inflection point is set at $65 \mathrm{~km} / \mathrm{h}$ and the emission rate at that point is set to $10 \mathrm{~g} / \mathrm{km}$. The emission rate is set to $100 \mathrm{~g} / \mathrm{km}$ and $50 \mathrm{~g} / \mathrm{km}$ when the vehicle speed is $0 \mathrm{~km} / \mathrm{h}$ and $140 \mathrm{~km} / \mathrm{h}$, respectively. The coefficients of the emission function satisfy the quadratic functions connecting the points specified above. While the inflection point was determined based on various predefined functions [41, 42], it has a somewhat exaggerated sensitivity to the speed-dependent emission factor. We intendedly set it more sensitive to speed in order to derive more explicit simulation results. Therefore, we presented outcome of mobile emissions not as grams but as percentage to deliver the information of increasing and decreasing trends of mobile emissions. For example, 90 means a $10 \%$ decrease in mobile emissions. In addition, while the infection point of $65 \mathrm{~km} / \mathrm{h}$ was obtained based on measurements of emissions of various vehicle types, fuel types, size, and vehicle years, the optimal eco-driving speed could be vary depends on vehicle size [43].

$$
\Theta= \begin{cases}0.02197(v-65)^{2}+10 & (0<v \leq 65) \\ 0.01244(v-65)^{2}+10 & (65<v \leq 140)\end{cases}
$$

\section{Results}

The development of platooning technology is environmentally desirable, but mitigating speed limit on motorways is environmentally unfavorable. According to Scenario 2, it is expected to reduce mobile emissions when the market share of AVs is less than $80 \%$. For example, when the market share of AVs is $50 \%$, the road capacity 


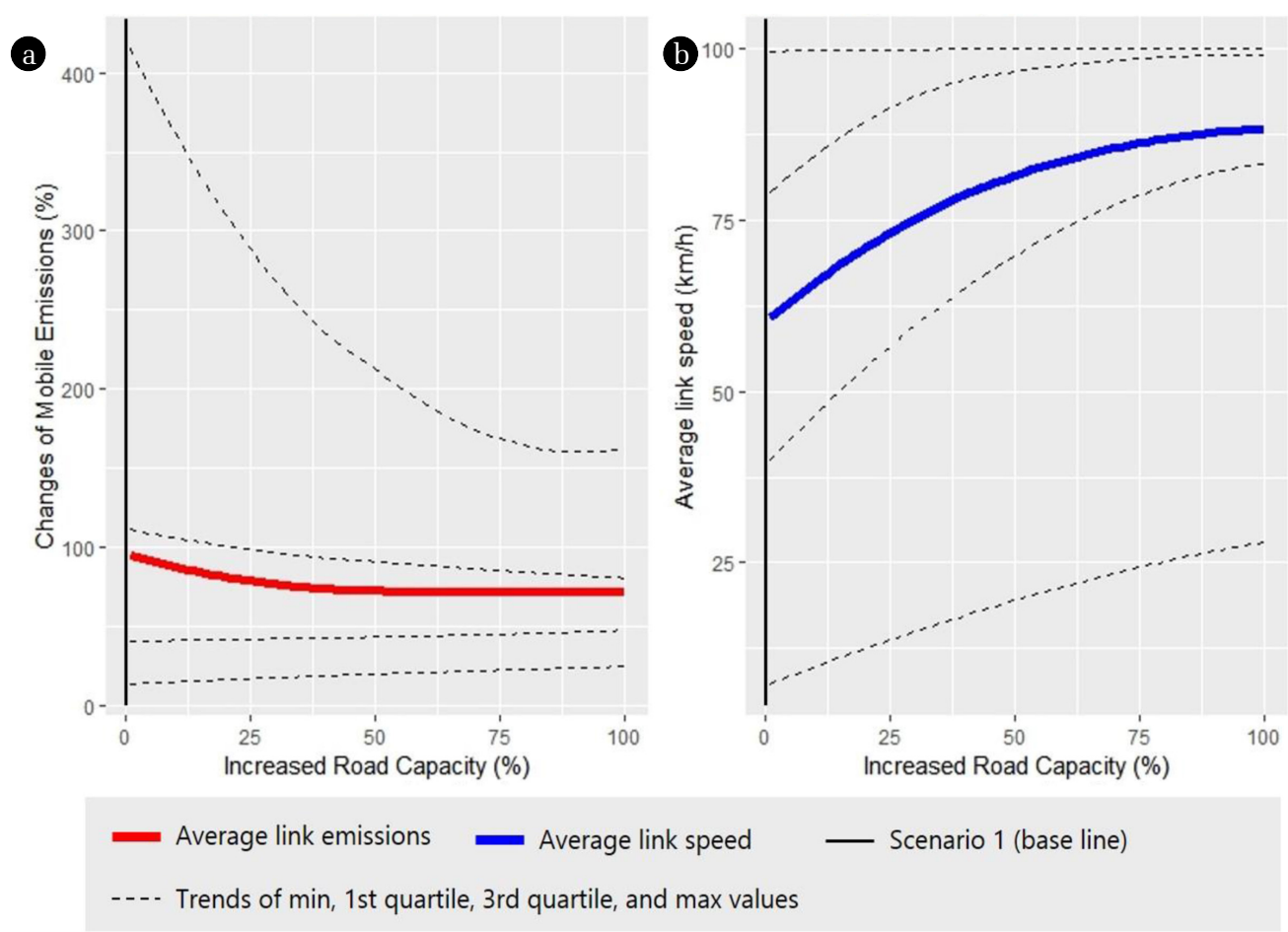

Fig. 1. Simulation outcomes of Scenario 2.

(Note: Changes in emissions were obtained by dividing the total emissions of the whole fleet from the change in road capacity by the total emissions from the baseline scenario.)

is increased by $18 \%$ [15]. In this case, when the inter-vehicle distance is decreased less than $20 \mathrm{~m}$, or 0.7 second when vehicle speed is $100 \mathrm{~km} / \mathrm{h}$ [15], the road capacity is increased more, and the mobile emissions reduction effect is expected due to the improved string stability (Fig. 1(a)). On the other hand, when the market share of AVs reached to $80 \%$, the road capacity is increased by $50 \%$ [15], and mobile emission reduction rate starts to stagnate from this point. It is difficult to expect the environmental benefit from this point on. However, the 3rd quartile and max lines of Fig. 1(a) shows that increased road capacity is effective in mitigating mobile emissions in high-emission areas regardless of the market share of AVs.

The main reason for the decrease in the total mobile emissions is due to the increase in the average link speed (Fig. 1(b)). As link capacity increases, links with slower initial link speeds approached link speed around $65 \mathrm{~km} / \mathrm{h}$, which emits the smallest mobile emissions per distance. In particular, the lowest speed link with an initial speed of only $5 \mathrm{~km} / \mathrm{h}$ increased to $28 \mathrm{~km} / \mathrm{h}$ when link capacity increased by $100 \%$. Since the traveling speed was limited to $100 \mathrm{~km} / \mathrm{h}$, links with high link speeds converged to $100 \mathrm{~km} / \mathrm{h}$ with increasing link capacity. Therefore, there was no rapid increase in link emissions due to high-speed driving.

According to Scenario 3, the change in total mobile emissions shows a decreasing and increasing concave trend as the driving speed limit increases (Fig. 2(a)). The inflection point is at the speed limit of $95 \mathrm{~km} / \mathrm{h}$, and this is the result of the offset between the increasing links and the decreasing link. The emissions of the highest emission link have declined gradually, but there are links that show a rapid increase in emissions as the 3rd quartile trend line shows.

A plausible conjecture for the existence of links with rapidly increasing emissions is due to the traffic volume that bypasses the congested links at high speeds as the travel speed limit increases. This conjecture is based on the fact that the trend of maximum values in Fig. 2(b) is equal to the travel speed limits. As the travel speed limit increases, the average link speed showed an increasing near-linear trend but the variance of link speed has also increased. It is interpreted that although some traffic flowed at high speed by bypassing the congestion links and resulting higher emissions, the dispersed traffic volume was insufficient to solve the congestion.

Fig. 3 shows four cross-sectional results of link-level mobile emissions for Scenarios 2 and 3, respectively. Fig. 3.1 confirms that the emissions from the high-emission links such as $(6,8)$, $(5,9),(11,12)$, and $(13,24)$ decreased sharply as the link capacity increases. In addition, Fig. 3.1(c) and 3.1(d) confirm that the emission reduction trend was stagnated when the link capacity increased by more than $50 \%$. Fig. 3.2 confirms that there are links that show a steep increase in emissions as the speed limit increases. In particular, the increasing trend of emissions from links $(1,2),(1,3)$, $(3,12)$, and $(12,13)$ demonstrates the previous conjecture that some vehicles generated more emissions by bypassing congested links with high speed.

In order to maximize the positive effect of AVs on the environment, continuous development and application of the platooning technology is necessary (Fig. 4(a)). Apart from the market share 

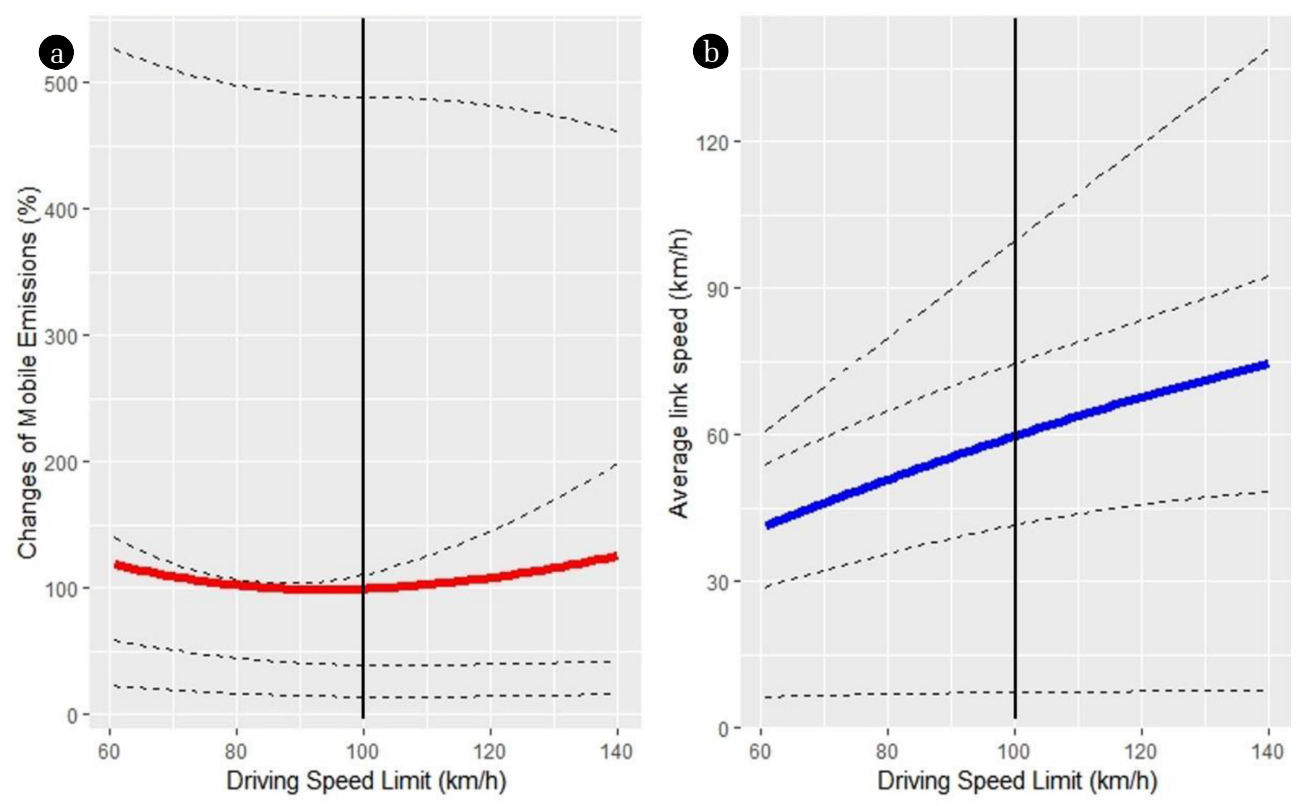

Average link emissions Average link speed

— Scenario 1 (base line)

-.-- Trends of min, 1st quartile, 3rd quartile, and max values

Fig. 2. Simulation outcomes of Scenario 3.

(Note: Changes in emissions were obtained by dividing the total emissions of the whole fleet from the change in speed limit by the total emissions from the baseline scenario.)

\section{Road capacity increase scenario simulation results}

(a) 0

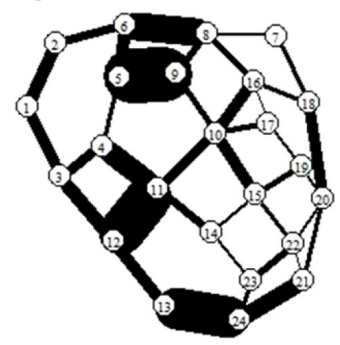

(b) $10 \%$ increase

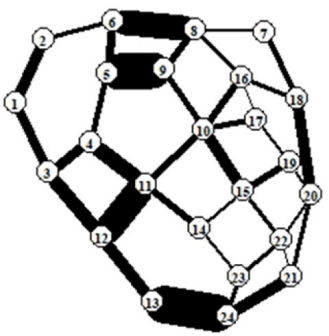

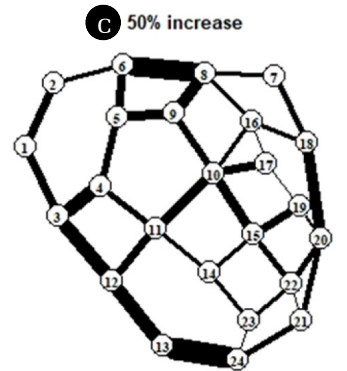

g Speed Limit $=100 \mathrm{~km} / \mathrm{h}$ (base scenario)

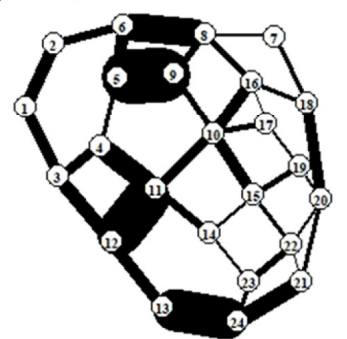

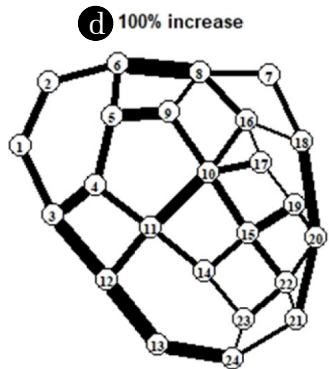

2. Driving speed limit increase scenario simulation results
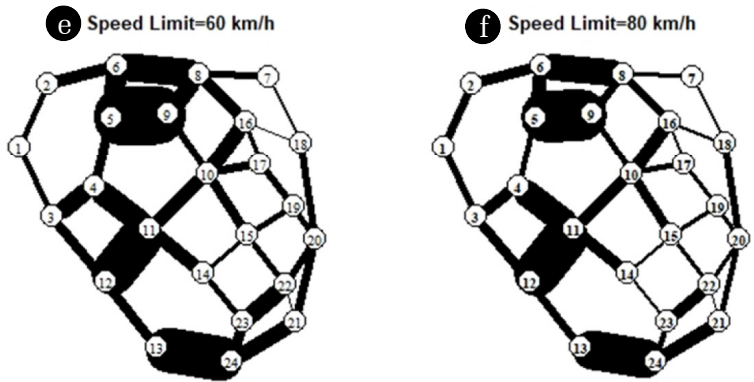

Fig. 3. Network visualizations of the mobile emission outcomes.

(The thickness of the links is proportional to the amount of emissions.) 

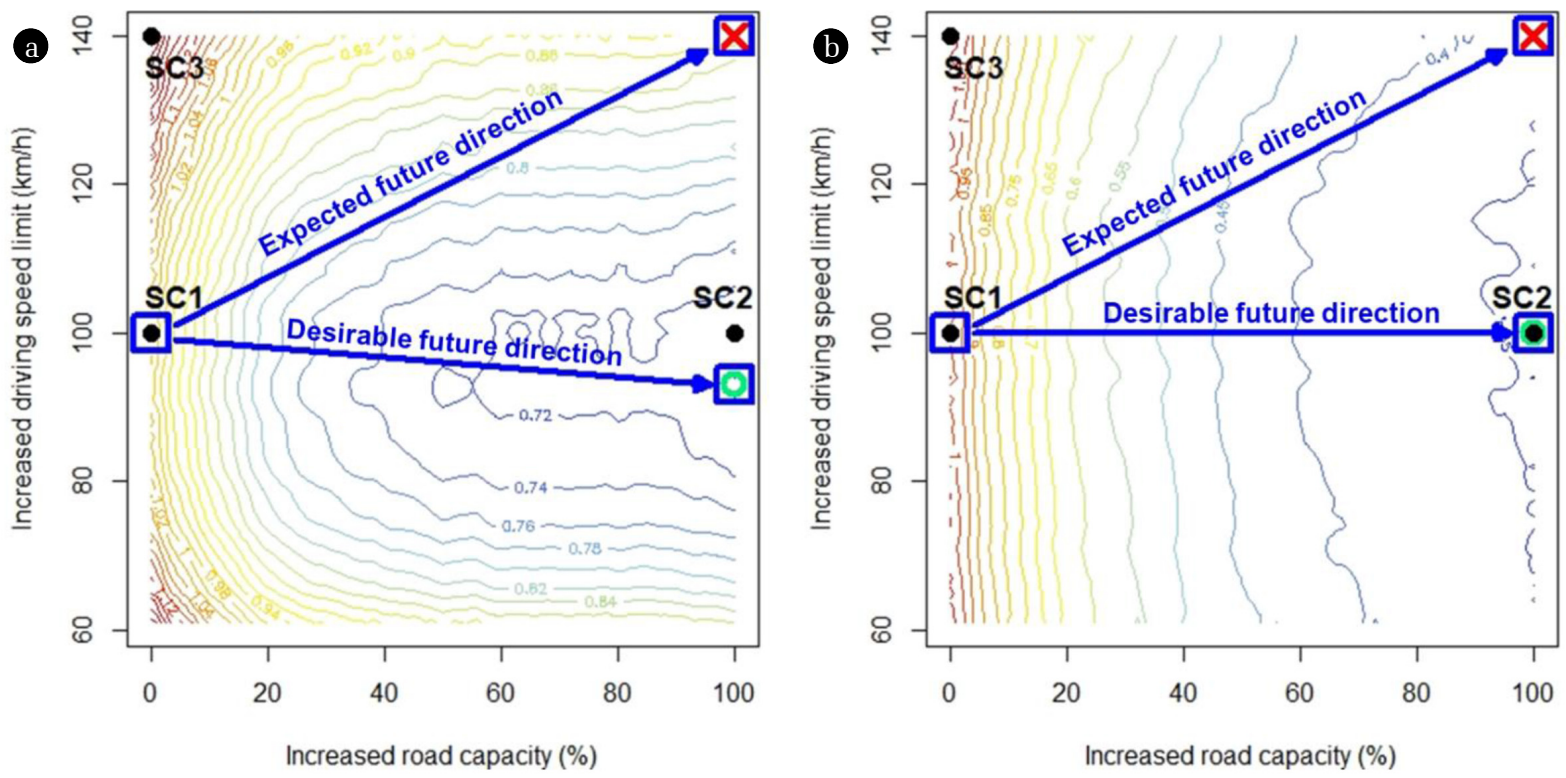

Fig. 4. Effects of the road capacity and speed limit increase effects on total mobile emissions and standard deviations. (a) Total mobile emissions, (b) SD of mobile emissions

of AVs, the reduction of the headway distance makes it possible to increase the road capacity additionally, which makes it possible to increase the road capacity beyond $100 \%$. However, easing the speed limit of motorways is not desirable from the environmental point of view because mobile emissions are increased due to vehicles that bypass at high speeds. These technical policy directions are effective not only in reducing the total amount of mobile emissions (Fig. 4(a)), but also in improving the areas experiencing extreme emissions (Fig. 4(b)). For example, if we follow the expected future direction, about $10 \%$ reduction of mobile emissions is expected, but if following the desirable future direction, about $30 \%$ reduction of mobile emissions is expected. To sum, it is clear that the vehicle platooning technology $[7,44]$ implemented at reasonable speed limits is one of the AV technologies that are very encouraging while increasing speed limit is not desirable from the environmental point of view.

\section{Conclusions and Discussion}

Some people may argue that mobile emission will not be a concern anymore in the era of AVs because electric vehicles (EVs) will become widespread. Furthermore, the combination of shared vehicles (SVs) and AVs will be the ultimate form of future transportation systems [45]. It is foreseen that in such an era, individuals will not own cars anymore but will consume vehicle services [46]. It will be a form of semi-public transportation system that vehicles move around without drivers, and people will use smart devices to call vehicles and pay as much as they use. According to this prospect, we cannot help but agree that the ultimate form of AV is a solar-powered EV. However, there are still at least two important reasons why we should pay attention to the effects of AVs on the reduction of air pollution.

First, there may be a considerable time gap between the widespread of AVs and EVs. While AVs are expected to be adopted in large-scale in various sectors by 2030, EVs have numerous obstacles to be tackled such as technology and market competitive issues before large-scale adoption [47-49]. Second, GHG reduction is a very urgent global issue, and AV technology can lead to immediate GHG reduction in the transportation sector. According to a recent study, if the share of renewable energy is increased by $2 \%$ a year, the tragedy caused by climate change cannot be stopped after 2035 [50]. In the Intergovernmental Panel on Climate Change Sixth Assessment Report [51], only the reduction of the fuel-carbon intensity by increasing the share of renewable energy is considered as the GHG reduction strategy of the transportation sector. This is because the improvement of the engine technology has not lead to substantive fuel efficiency improvement due to the increase of the functions and the weight of vehicles [52]. However, the recent development of the ITS and the AV technology are expected to improve the fuel efficiency and reduce the GHG emissions accordingly.

It is not easy to predict all the changes that will occur caused by the large-scale adoption of AVs. Of the many predictions currently being discussed, the following three factors must be considered in subsequent studies. First, it is necessary to predict the increase in traffic demand due to the introduction of AVs. While the current study conducted with the fixed traffic demand assumption, AVs will increase traffic demand by providing mobility for the underserved population [2, 16, 53, 54], by shifting mode of transportation [17], and by providing easier travel [55-58]. Since the degree of congestion varies according to the traffic volume, the simulation results may change if the traffic demands changes. Second, we need to consider the system of combining AVs and car sharing services [59]. The AV taxi service was first introduced by Waymo in December 2018 in Phoenix, Arizona, USA [60]. Under such a system, AVs will no longer stay in parking lots, but will drive more distances to generate more profit. In this case, mobile emissions 
can be increased not by technological development, but by the way of people's utilization or operation systems of AVs. Therefore, the operational aspects of AVs should be investigated along with the technical aspects.

Lastly, the development directions of AV technology and policies discussed in this study should be considered together with safety issues. The simulation results show that narrowing the inter-vehicle distance has an excellent effect in reducing the mobile emissions and spatial deviation. But the narrower the inter-vehicle distance, the higher the risk of a collision in unexpected incidents. Also, the higher driving speed is, the greater the damage to people and property in accidents. Although the current study shows that increasing the speed limit is not environmentally desirable, increasing demand for long-distance transport, including the cargo transport sector, can lead to a discussion of easing speed limits on freeways to reduce transportation cost.

This study assumes that the average link speed of the null scenario is $60 \mathrm{~km} / \mathrm{h}$ in order to assume the general situation. This is the level of service at the suburban level [42]. However, the results of this study cannot be generalized to urban areas in metropolitan cities whose average vehicle speed is less than $30 \mathrm{~km} / \mathrm{h}$ or to suburban motorways with average vehicle speed approaching the speed limit. In order to fill this gap, a study to measure the effect of introducing AVs with varying average speeds or to compare urban, rural, and suburban conditions should be conducted in subsequent studies. In addition, this study is useful for showing the overall trend because it uses the conceptual simulation model and simplified parameters, but it is inappropriate to predict the future that will occur in a specific area. Therefore, further studies that combine a more sophisticated model such as an agent-base model and the composition of the local vehicle fleet are required.

\section{Acknowledgments}

This research was jointly supported by a grant (NRF-2017M3D8 A1092021) from the National Strategic Project-Fine Particle of the National Research Foundation of Korea (NRF) funded by the Ministry of Science and ICT (MSIT), the Ministry of Environment (ME), and the Ministry of Health and Welfare (MOHW), and a grant (NRF-2018R1D1A1B07047033) from the Basic Science Research Program through the National Research Foundation of Korea (NRF) funded by the Ministry of Education.

\section{References}

1. Miller SA, Heard BR. The environmental impact of autonomous vehicles depends on adoption patterns. Environ. Sci. Technol. 2016;50:6119-6121.

2. Fagnant DJ, Kockelman K. Preparing a nation for autonomous vehicles: Opportunities, barriers and policy recommendations. Transp. Res. Part A Policy Pract. 2015;77:167-181.

3. Bansal P, Kockelman KM. Forecasting Americans' long-term adoption of connected and autonomous vehicle technologies. Transp. Res. Part A Policy Pract. 2017;95:49-63.

4. Alexander D, Gartner J. Self-driving vehicles, advanced driver assistance systems, and autonomous driving features: Global market analysis and forecasts. Navigant Consulting, Inc.; 2014.

5. Bierstedt J, Gooze A, Gray C, Peterman J, Raykin L, Walters J. Effects of next-generation vehicles on travel demand and highway capacity. FP Think Working Group; 2014. p. 10-11.

6. Laslau C, Holman M, Saenko M, See K, Zhang Z. Set autopilot for profits: Capitalizing on the $\$ 87$ billion self-driving car opportunity. Lux Research; 2014.

7. Litman T. Autonomous vehicle implementation predictions. Victoria, Canada: Victoria Transport Policy Institute; 2017.

8. Anenberg SC, Miller J, Minjares R, et al. Impacts and mitigation of excess diesel-related $\mathrm{NO}_{\mathrm{x}}$ emissions in 11 major vehicle markets. Nature 2017;545:467-471.

9. Huang Y, Ng ECY, Zhou JL, Surawski NC, Chan EFC, Hong G. Eco-driving technology for sustainable road transport: A review. Renew. Sust. Energ. Rev. 2018;93:596-609.

10. Huang Y, Organ B, Zhou JL, et al. Remote sensing of on-road vehicle emissions: Mechanism, applications and a case study from Hong Kong. Atmos. Environ. 2018;182:58-74.

11. EPA. Environmental Protection Agency releases MOVES 2010 Mobile Source Emission Model: Questions and Answers. G. EPA-420-F-09-073, Washington D.C.; 2009.

12. Los B, Timmer MP, de Vries GJ. How global are global value chains? A new approach to measure international fragmentation. J. Reg. Sci. 2015;55:66-92.

13. Fernandes P, Nunes U. Platooning with IVC-enabled autonomous vehicles: Strategies to mitigate communication delays, improve safety and traffic flow. IEEE Trans. Intell. Transp. Syst. 2012;13:91-106.

14. Fernandes P, Nunes U. Platooning of autonomous vehicles with intervehicle communications in SUMO traffic simulator. In: 13th International IEEE Conference on Intelligent Transportation Systems; 19-22 September 2010; Funchal, Portugal: IEEE.

15. Shladover SE, Su D, Lu X-Y. Impacts of cooperative adaptive cruise control on freeway traffic flow. Transp. Res. Rec. 2012; 2324:63-70.

16. Brown A, Gonder J, Repac B. An analysis of possible energy impacts of automated vehicles. In: Road vehicle automation. New York: Springer; 2014. p. 137-153.

17. Stephens TS, Gonder J, Chen Y, Lin Z, Liu C, Gohlke D. Estimated bounds and important factors for fuel use and consumer costs of connected and autonomous vehicles. No. NREL/TP5400-67216. Golden CO, United States: National Renewable Energy Lab. (NREL); 2016.

18. Horowitz R, Varaiya P. Control design of an automated highway system. Proc. IEEE 2000;88:913-925.

19. Milanes V, Villagra J, Godoy J, Simo J, Pérez J, Onieva E. An intelligent V2I-based traffic management system. IEEE Trans. Intell. Transp. Syst. 2012;13:49-58.

20. Van der Voort M, Dougherty MS, van Maarseveen M. A prototype fuel-efficiency support tool. Transp. Res. Part C Emerg. Technol. 2001;9:279-296.

21. Wu C, Zhao G, Ou B. A fuel economy optimization system with applications in vehicles with human drivers and autonomous vehicles. Transp. Res. Part D Transp. Environ. 2011;16:515-524.

22. Talebpour A, Mahmassani HS. Influence of connected and autonomous vehicles on traffic flow stability and throughput. 
Transp. Res. Part C Emerg. Technol. 2016;71:143-163.

23. Wadud Z, MacKenzie D, Leiby P. Help or hindrance? The travel, energy and carbon impacts of highly automated vehicles. Transpor. Res. Part A Policy Pract. 2016;86:1-18.

24. Tientrakool P, Ho Y-C, Maxemchuk NF. Highway capacity benefits from using vehicle-to-vehicle communication and sensors for collision avoidance. In: 2011 IEEE Vehicular Technology Conference (VTC Fall); 5-8 September 2011; San Francisco, CA, USA: IEEE.

25. Atiyeh C. Predicting traffic patterns, one Honda at a time. MSN Auto; June 2012.

26. Scholz T, Schmallowsky A, Wauer T. Auswirkungen eines allgemeinen tempolimits auf autobahnen im land brandenburg [Internet]. Schlothauer \& Wauer; c2007. Available from: http://www.mil.brandenburg.de/media_fast/4055/studie_tempolimit.pdf.

27. Yu S, Shi Z. Dynamics of connected cruise control systems considering velocity changes with memory feedback. Measurement 2015;64:34-48.

28. Bose A, Ioannou PA. Analysis of traffic flow with mixed manual and semiautomated vehicles. IEEE Trans. Intell. Transp. Syst. 2003;4:173-188.

29. Tang TQ, Li JG, Huang HJ, Yang XB. A car-following model with real-time road conditions and numerical tests. Measurement 2014;48:63-76.

30. Yu S, Shi Z. An extended car-following model considering vehicular gap fluctuation. Measurement 2015;70:137-147.

31. Yu S, Shi Z. An improved car-following model considering relative velocity fluctuation. Commun. Nonlinear Sci. Numer. Simul. 2016;36:319-326.

32. Abou-Senna H, Radwan E. VISSIM/MOVES integration to investigate the effect of major key parameters on $\mathrm{CO}_{2}$ emissions. Transp. Res. Part D Transp. Environ. 2013;21:39-46.

33. Abou-Senna H, Radwan E, Westerlund K, Cooper CD. Using a traffic simulation model (VISSIM) with an emissions model (MOVES) to predict emissions from vehicles on a limited-access highway. J. Air Waste Manage. Assoc. 2013;63:819-831.

34. Shah R, Nezamuddin N, Levin MW. Supply-side network effects on mobile-source emissions. Transp. Policy 2018 (in press).

35. Stevanovic A, Stevanovic J, Zhang K, Batterman S. Optimizing traffic control to reduce fuel consumption and vehicular emissions: Integrated approach with VISSIM, CMEM, and VISGAOST. Transp. Res. Rec. 2009;2128:105-113.

36. Boyce D. Forecasting travel on congested urban transportation networks: Review and prospects for network equilibrium models. Netw. Spat. Econ. 2007;7:99-128.

37. Lee S. Mathematical programming algorithms for equilibrium road traffic assignment [dissertation]. London: Univ. of London; 1995.

38. LeBlanc LJ, Morlok EK, Pierskalla WP. An efficient approach to solving the road network equilibrium traffic assignment problem. Transp. Res. 1975;9:309-318.

39. United States, Bureau of Public Roads. Traffic assignment manual for application with a large, high speed computer. Washington D.C.: US Department of Commerce, Bureau of Public Roads, Office of Planning Urban Planning Division; 1964.

40. Frank M, Wolfe P. An algorithm for quadratic programming. Nav. Res. Logist. 1956;3:95-110.
41. National Institute of Environmantal Research. Air pollutant emission factors: Estimated by 2012 emissions. Ministry of Environment, Incheon, Republic of Korea. 2015 (Korean).

42. Li Y, Pearson B, Murrells T. Updated vehicle emission curves for use in the National Transport Model. Report to the Department for Transport; 2009.

43. Wang J, Rakha HA. Fuel consumption model for conventional diesel buses. Appl. Energ. 2016;170:394-402.

44. Kamali M, Dennis LA, McAree O, Fisher M, Veres S. Formal verification of autonomous vehicle platooning. Sci. Comput. Prog. 2017;148:88-106.

45. Iacobucci R, McLellan B, Tezuka T. Modeling shared autonomous electric vehicles: Potential for transport and power grid integration. Energy 2018;158:148-163.

46. Elliott C. Should you buy a new car? Read this first. In: Forbes; 14 November 2018.

47. Varun M, Kumar C. Problems in electric vehicles. Int. J. Appl. Res. Mech. Eng. 2012;2:63-73.

48. Toma S. Six problems with electric cars that nobody talks about. In: Autoevolution; 6 November 2017.

49. Massey J. Charging electric vehicles: The challenges ahead. In: energypost.eu.; 8 February 2018.

50. Aengenheyster M, Feng QY, Ploeg F, Dijkstra HA. The point of no return for climate action: Effects of climate uncertainty and risk tolerance. Earth Syst. Dynam. 2018;9:1085-1095.

51. IPPC. Intergovernmental panel on climate change. In: IPCC Sixth Assessment Report; 2018.

52. US Environmental Protection Agency. Light-duty automotive technology, carbon dioxide emissions, and fuel economy trends: 1975 through 2017; January 2018.

53. Harper C, Mangones S, Hendrickson C, Samaras C. Bounding the potential increases in vehicles miles traveled for the non-driving and elderly populations and people with travel-restrictive medical conditions in an automated vehicle environment. In: Trnsportation Research Board 94th Annual Meeting; 11-15 January 2015; Washington D.C.

54. MacKenzie D, Wadud Z, Leiby P. A first order estimate of energy impacts of automated vehicles in the United States. In: Transportation Research Board Annual Meeting; Washington D.C.; 2014. p. 12-16.

55. Childress S, Nichols B, Charlton B, Coe S. Using an activity-based model to explore the potential impacts of automated vehicles. Transp. Res. Rec. 2015;2493:99-106.

56. Gucwa M. Mobility and energy impacts of automated cars. In: Proceedings of the Automated Vehicles Symposium; San Francisco; 2014.

57. Hymel KM, Small KA, Van Dender K. Induced demand and rebound effects in road transport. Transp. Res. Part B Methodol. 2010;44:1220-1241.

58. Cervero R. Induced demand: An urban metropolitan perspective. Univ. of California Transportation Center; UC Berkeley; 2001.

59. Fagnant DJ, Kockelman KM. The travel and environmental implications of shared autonomous vehicles, using agent-based model scenarios. Transp. Res. Part C Emerg. Technol. 2014;40:1-13.

60. Wang B. Waymo started its commercial self-driving ride sharing service. In: NextBigFuture; 6 December 2018. 